\title{
On the equal variables method applied to real variables
}

\section{VASILE CÎRTOAJE}

\section{ABSTRACT.}

As it is known, the equal variables method can be used to create and solve difficult symmetric inequalities in nonnegative variables involving the expressions $x_{1}+x_{2}+\cdots+x_{n}, x_{1}^{k}+x_{2}^{k}+\cdots+x_{n}^{k}$ and $f\left(x_{1}\right)+f\left(x_{2}\right)+\cdots+f\left(x_{n}\right)$, where $k$ is a real constant, and $f$ is a differentiable function on $(0, \infty)$ such that $g(x)=f^{\prime}\left(x^{\frac{1}{k-1}}\right)$ is strictly convex. In this paper, we extend the equal variables method to real variables.

\section{REFERENCES}

[1] Bennett, G., A p-free lp-inequality, J. Math. Inequal., 3 (2009), No. 2, 155-159

[2] Cîrtoaje, V., Algebraic inequalities - Old and new methods, GIL Publishing House, Zalau, 2006

[3] Cîrtoaje, V., The equal variables method, JIPAM. J. Inequal. Pure Appl. Math., 8 (2007), No. 1, Art. 15, 21 pp.

UNIVERSITY OF PLOIESTI

DEPARTMENT OF CONTROL AND COMPUTERS

BDUl BuCURESTi 39, RO-100680 Ploiesti, ROMANiA

E-mail address: vcirtoaje@upg-ploiesti.ro 